\title{
Exploration and exploitation of food sources by social insect colonies: a revision of the scout-recruit concept
}

Received: 29 December 1999 / Revised: 25 February 2000 / Accepted: 16 October 2000

\begin{abstract}
Social insect colonies need to explore and exploit multiple food sources simultaneously and efficiently. At the individual level, this colony-level behaviour has been thought to be taken care of by two types of individual: scouts that independently search for food, and recruits that are directed by nest mates to a food source. However, recent analyses show that this strict division of labour between scouts and recruits is untenable. Therefore, a modified concept is presented here that comprises the possible behavioural states of an individual forager (novice forager, scout, recruit, employed forager, unemployed experienced forager, inspector and reactivated forager) and the transitions between them. The available empirical data are reviewed in the light of both the old and the new concept, and probabilities for the different transitions are derived for the case of the honey-bee. The modified concept distinguishes three types of foragers that may be involved in the exploration behaviour of the colony: novice bees that become scouts, unemployed experienced bees that scout, and lost recruits, i.e. bees that discover a food source other than the one to which they were directed to by their nest mates. An advantage of the modified concept is that it allows for a better comparison of studies investigating the different roles performed by social insect foragers during their individual foraging histories.
\end{abstract}

Keywords Social insects $\cdot$ Scout $\cdot$ Recruit . Communication $\cdot$ Foraging

Communicated by R.F.A. Moritz

J.C. Biesmeijer $(\square) \cdot$ H. de Vries

Ethology and Socio-Ecology Group, Utrecht University, P.O. Box 80.086, 3508 TB Utrecht, The Netherlands

Present address:

J.C. Biesmeijer, Apartado Postal 2270-3000, Heredia, Costa Rica, e-mail: kbiesmei@sol.racsa.co.cr,

Tel.: +506-2602082, Fax +506-2377043

\section{Introduction}

The development of adequate concepts is essential for understanding and explaining a phenomenon. The means by which some behavioural phenomenon, for example the foraging behaviour of bees, becomes intelligible is through concepts. Probably the ultimate goal of all empirical research is to develop adequate concepts of the real world.

In ethological research, as of course in many other disciplines, a behavioural phenomenon is often described in terms already known from other contexts. On the basis of a more or less superficial similarity between the observed behaviour of the animal and the well-known behaviour in everyday human life, the behaviour is, at least provisionally, referred to using the familiar everyday term. There is nothing wrong with this practice, although one possible pitfall might be that the animal's behaviour is interpreted too much in the light of the conceptual meaning connected originally to the term. Another pitfall might be that on closer examination, the behaviour turns out to be quite different from the one that originally served to make the behaviour intelligible. Consequently, each concept, especially one borrowing terminology from other contexts, should be reviewed continuously with respect to its empirical adequacy and the consistency of the terms used for referring to the concept.

One example of a borrowed concept in behavioural ecology is that in which the terms scout and recruit are used to characterise the two types of forager that by means of a communication system allow a social insect colony to explore and exploit food sources efficiently. The terms scout and recruit are widely used in military practice where a scout is sent out to acquire information about the enemy's position, strength etc., and a recruit is a newly enlisted not yet fully trained serviceman or servicewoman (Concise Oxford Dictionary 1991). Here, the two terms clearly refer to individuals that perform different tasks: a scout explores, whereas recruits never decide by themselves, but are guided by the scout's information. The army scout-recruit concept involves obtaining a 
thorough knowledge of the opponent's forces while investing just enough exploratory effort. A social insect colony strives to obtain a continuous flow of accurate information concerning food source availability in its foraging range to facilitate continuous harvest of the highest-quality food. The objectives of army and insect colony are very similar; hence the use of army terms to characterise social insect foraging.

Recent advances in our understanding of the organisation of foraging in social insects, however, reveal that maintaining the strict classification of foragers in scouts and recruits is untenable (Deneubourg et al. 1983, 1987; Seeley 1983, 1985, 1995; Pasteels et al. 1987; de Vries and Biesmeijer 1998). This led us to develop a modified concept that describes both the different behavioural states of a forager and the transitions that may occur from one state to another. In this review, we will first discuss the history of and problems with the old concept, followed by the introduction of the new concept and an evaluation of the adequacy of the two concepts given the available information on social insect collective foraging.

\section{The history of the scout-recruit concept}

Already before the early work of Karl von Frisch on the language of the bees (1923), a distinction was made between individual ants, bees or wasps that search for food sources and individuals that collect the food. The searching individuals were referred to as 'searchers' (Bonnier 1906 in Ribbands 1953) or 'explorers' (Maeterlinck $1901 / 1946$, p. 127), whereas the food-collecting individuals were referred to as 'collectors' (Bonnier 1906 in Ribbands 1953). von Frisch (1918, pp. 141-142; 1919, pp. 159-164) first followed the above distinction and notes (1919, p. 159) that the terms 'searcher' and 'collector' do not refer to different classes of individuals, but to different tasks that individuals perform. Later, von Frisch (1923, pp. 120-121) suggested a division into three groups: collectors ('Sammlern'), primary searchers ('primären Suchern') and secondary searchers ('sekundären Suchern'). He defined primary searchers as those individuals that search for food uninformed, and secondary searchers as those using information obtained from (the round dance performed by) nest mates. While studying odour-learning behaviour of honey-bees, Opfinger (1949, p. 452) could distinguish three types of bee based upon their learning behaviour: (1) those bees that faithfully adhere even to poor sources; (2) those bees, the majority, that continue to visit a source only as long as it supplies food normally, and (3) a small group of bees that were especially restless, were always searching around and were more likely to discover new food sources. At the same time, zu Oettingen-Spielberg (1949) used the term search bee ('Suchbiene') for both the unexperienced bees that locate a food source and for those bees that are recruited by round dances for an artificial feeder, but found instead the flowers with a different odour $8 \mathrm{~m}$ away from the feeder. Ribbands (1953, pp. 100-104) and von Frisch (1950) refer to zu Oettingen-Spielberg's (1949) 'Suchbiene' as a scout. Ribbands (1953) states that since scout bees are usually established foragers, their searching may be guided by previous experience. Similarly, Lindauer (1953) uses the term scout bee as a translation for 'Suchbiene' in a foraging context (Lindauer 1952) and again (Lindauer 1957) to refer to those bees of a swarm indicating suitable nest sites (called 'Spurbiene' in Lindauer 1955). Since that time, the term scout has been used by most researchers to indicate both individuals that discover new food sources and those locating new nest sites (e.g. Seeley 1985, 1995; Winston 1987; Dreller 1998). However, the definitions used by the various authors to characterise a scout differ considerably. The problems related to these differences in interpretation are explained below.

\section{Problems with the scout-recruit concept}

The colony-level behaviour of exploring and exploiting food sources is not necessarily directly reflected in the individual-level behaviours scouting and being recruited. Not every scout discovers a food source new to the colony and not every recruit locates the food source indicated by its nest mates (Fig. 1, Table 1). Both terms refer to a

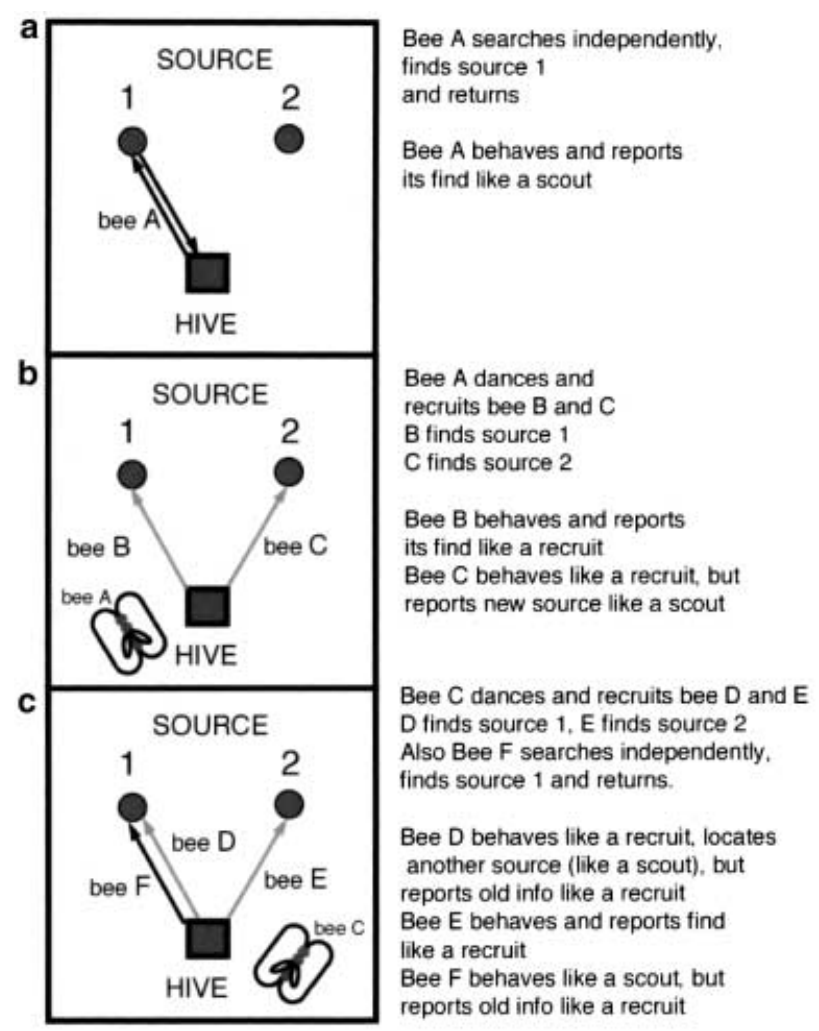

Fig. 1a-c Illustration of the problems related to the characterisation of foragers using the strictly dichotomous concept of scout and recruit. The figures represent the case of a honey-bee colony discovering and exploiting two food sources 
behavioural characteristic of an individual searching for food: scouts search independently, whereas recruits are informed by nest mates about the presence of a food source and use that information to search the source. The success of this searching behaviour is, therefore, not relevant for an individual's characterisation as scout or recruit. However, a forager's success is included in some of the recruit definitions (Seeley 1995), but generally not in the scout definition (Seeley 1983, 1995; but see Winston 1987).

The ambiguity in the scout-recruit concept hampers our progress in understanding the collective foraging behaviour of social insects (de Vries and Biesmeijer 1998; Biesmeijer and Ermers 1999) as can be illustrated by the following example. Seeley (1983) analysed the division of labour between scouts (independent searchers) and recruits (dance-guided searchers) in honey-bees. However, when some recruits located food sources other than those indicated by the dance, he had to change his definitions to explain the individual behaviour in light of the colony's foraging strategy. He included the "bees which followed dances but nevertheless scouted", i.e. foraged at another patch than indicated by the dances they fol-

Table 1 Summary of the behaviours and information status of the bees from Fig. 1 ( - no external information used)

\begin{tabular}{llll}
\hline Bee & $\begin{array}{l}\text { Scout or recruit at } \\
\text { start of search? }\end{array}$ & $\begin{array}{l}\text { Found source } \\
\text { according to } \\
\text { external } \\
\text { information use? }\end{array}$ & $\begin{array}{l}\text { Discovered food } \\
\text { source new to } \\
\text { the colony? }\end{array}$ \\
\hline A & Scout & - & Yes \\
B & Recruit & Yes & No \\
C & Recruit & No & Yes \\
D & Recruit & No & No \\
E & Recruit & Yes & No \\
F & Scout & - & No \\
\hline
\end{tabular}

lowed, in the group of scouts. Doing so, the type of information brought into the hive (part of the colony-level behaviour) determined the status of such bees and not the stimuli that instigated their searching (individuallevel behaviour).

\section{The modified concept: behaviour control structure of a social forager}

The main problem connected with the 'old' scout-recruit concept appears to be that this static, dichotomous notion is not adequate to cover the dynamic foraging histories of individual foragers. A more extended forager concept, one that encompasses the refined concepts of scout, recruit, employed and unemployed forager, experienced and novice forager, inspector and reactivated forager, is needed to understand social insect foraging (de Vries and Biesmeijer 1998; Biesmeijer and Ermers 1999). In this paper, we propose such a concept that is based on representing a behaving individual by a behaviour control structure (BCS). A BCS instantiates the rules that regulate the behaviour of an individual, in this case a foraging insect. For the behaviour we are considering, it comprises seven mutually exclusive behavioural categories as well as the transitions between them (Fig. 2, Table 2). In her life as forager, a social insect traverses several of these different behaviour states, depending on the internal and external circumstances and information available to her.

The categories novice forager and recruit are defined in accordance with most other authors (von Frisch 1967/1993; Seeley 1983, 1995). One should note, however, that according to this definition, a recruit does not have to find a food source to be categorised as a recruit (as is required by the definition of Winston 1987).
Fig. 2 Behaviour control structure of a social insect forager. Depicted are the seven behavioural categories of foragers distinguished in the new concept, the proposed transitions from one category to another and the information on which the transitions are based. The left part of the diagram represents internally driven categories, the right part, the externally driven categories. Upon locating a rich source, a searching forager becomes employed, whereas upon locating a poor source (including no source), a searching forager returns to the hive and becomes unemployed. For detailed explanation of the concept, see the text

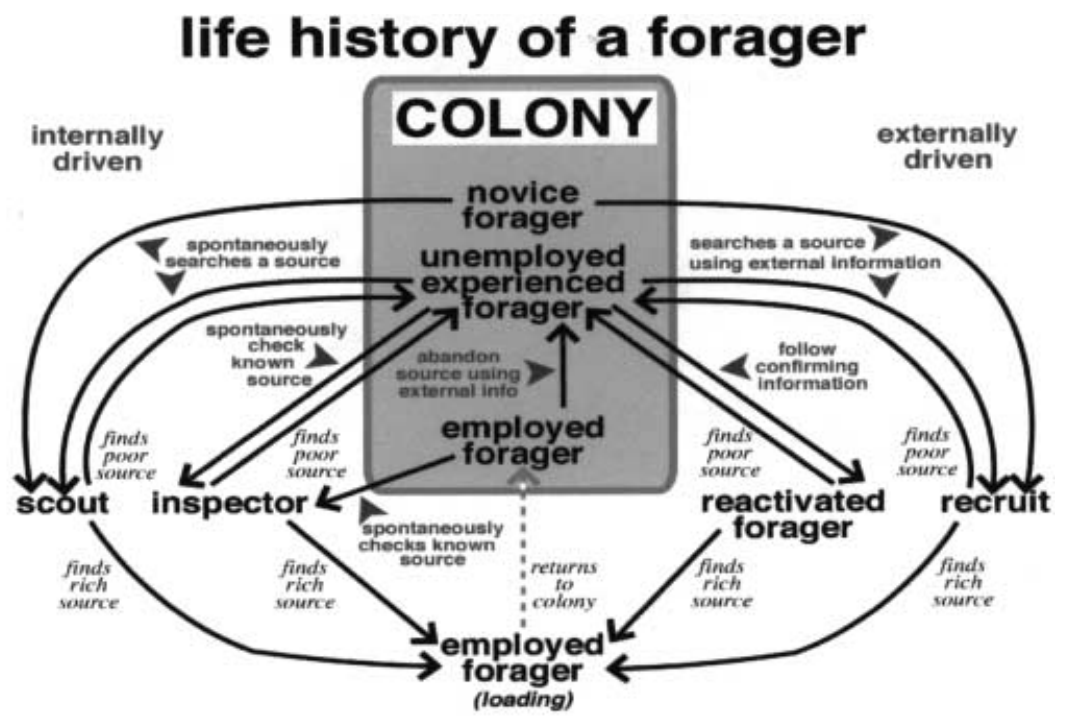

FIELD 
Table 2 Definitions of the various behaviour categories or states of a social insect forager

\begin{tabular}{ll}
\hline Behaviour category & Definition \\
\hline Novice forager & Individual inside the colony, without any foraging experience \\
Scout & Individual using internal information only to search for a food source not previously known to her \\
Recruit & Individual using external information to search for a food source not previously known to her \\
Employed forager & Individual that knows and exploits a profitable source; she does not follow external information \\
Unemployed experienced forager & Individual inside the colony, with previous experience, but not engaged in foraging \\
Inspector & $\begin{array}{c}\text { Individual, (temporarily) not engaged in foraging, that spontaneously revisits a previous } \\
\text { food source } \\
\text { Reactivated forager }\end{array}$ \\
& $\begin{array}{c}\text { Individual, (temporarily) not engaged in foraging, that revisits a previous site after having } \\
\text { obtained external information about that site }\end{array}$ \\
\hline
\end{tabular}

A scout is an individual that starts searching for an unknown food source without using information communicated by nest mates. Thus, independent search is required, not the discovery of a food source (as is required by the definitions of Lindauer 1952 and Winston 1987).

The term employed forager follows Seeley (1995, p. 85). An unemployed experienced forager is an experienced forager inside the hive and not engaged in foraging (or searching).

Two new categories, inspector and reactivated forag$e r$, are introduced for temporarily unemployed individuals that revisit the food source they frequented previously, either spontaneously (inspector), i.e. based on their memory, or after having obtained updated information from nest mates about their previous source (reactivated forager).

A potential forager starts her foraging career as a novice forager. This novice forager becomes a scout or a recruit as soon as she starts searching for a source (Fig. 2), either spontaneously (scout) or after following external information (recruit). An individual searching for a food source (either as a recruit or as a scout) becomes an employed forager when she actually finds a food source and engages in food collecting, or becomes an unemployed experienced forager as soon as she has returned to the nest without a load (because she did not find a sufficiently rich source). Likewise, an unemployed experienced forager may become a scout, recruit, inspector or reactivated forager, depending on whether she starts searching or checking a source spontaneously or starts doing so using external information. Novice foragers and unemployed foragers form the colony's supply of foragers inside the hive. Scouts and recruits search for food sources unknown to them, inspectors and reactivated foragers go to food sources they visited previously. An employed forager returning to the nest with a load becomes an unemployed forager when she is unable to deliver her load quickly enough or has experienced poor foraging at the source, otherwise she will, after unloading and perhaps communicating, go out again to inspect her known source. From Fig. 2, it becomes clear that most categories can be reached by more than one trajectory. Hence, the importance of including the forager's history in characterising an individual forager.

It is important to stress that for this particular BCS to be empirically adequate, all possible individual foraging histories should be implicit in it. If in future empirical work, a forager history is observed that cannot be derived from the current BCS, this BCS is not a valid representation of a social insect forager.

Note that the BCS presented here only covers (intentionally) the foraging histories of insects that forage socially, not solitarily. Although in principle the BCS could be extended to include solitarily foraging social insects as well, it seems better to reserve a separate BCS for these foragers, such as found in bumble-bees (Heinrich 1976, 1979), several ants (Hölldobler and Wilson 1990) and possibly some stingless bees (Johnson 1983), since solitary foragers are necessarily both explorers and exploiters.

The BCS could be extended to include rules that control other tasks, such as food storing and food processing. In principle, the whole life history of the individual insect could be represented by such a highly elaborated BCS. In this way, a concept of an organism as a life-long behaving individual is obtained (Goodwin and Dawkins 1995).

\section{The adequacy of the concepts with respect to empirical results}

In this section we will analyse the extent to which our concept fits the empirical data. The status of foragers will be analysed using both the traditional and modified concepts and terminology. The following studies that explicitly address the behaviour of scouts and recruits will be analysed (summarised in Table 3): von Frisch (1923), zu Oettingen-Spielberg (1949), Lindauer (1952, 1953), Seeley (1983), Crawford and Rissing (1983), Pereboom and Sommeijer (1993), Fourcassié and Traniello (1994), Howard et al. (1996), Dreller (1998) and Biesmeijer et al. (1998).

von Frisch (1923) first studied the behaviour of temporarily unemployed bees that used to feed at an artificial feeder (Fig. 3a, trajectory 1-4). Twelve (71\%) of 17 unemployed experienced bees 'scouted' spontaneously ('Kundschafter') the known food source, using their time sense about the opening of the source (transition 5). Such bees would be referred to as inspectors in our concept. Moreover, he studied reactivation (transition 6), i.e. the recruitment of unemployed experienced bees to a 

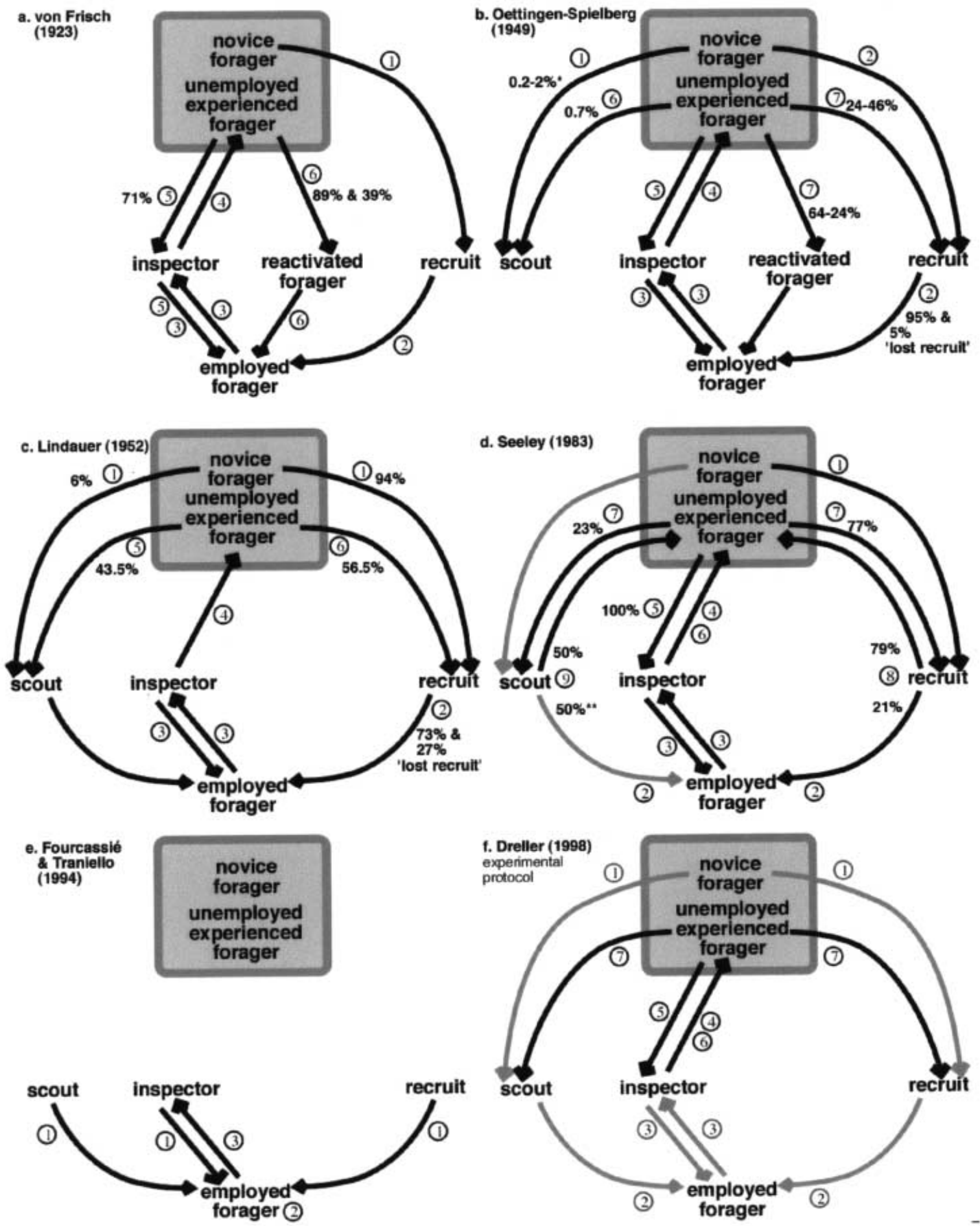

Fig. 3a-f The experimental procedures and results from six studies on individual behaviour of social insect foragers represented according to the terminology used in the new concept (a-d, $\mathbf{f}$ honey-bees; e ants). For detailed information see text. Encircled numbers indicate the trajectory that foragers followed in each study. Transition percentages obtained in each study are given next to the respective transition arrows. Grey arrows represent transitions inferred from the study that were not explicitly part of the experi-

mental procedure. As a simplification we take together 'employed foragers at source' and 'employed foragers in colony', which were presented separately in Fig. 2. b *Estimation based on the 1-10 bees of the 500-600 bees actively flying around that located the food offered while all bees were captured upon discovering the food (zu Oetingen-Spielberg 1949). d **Calculated from Seeley (1983) and Seeley and Visscher (1988) 
Table 3 Terms used in previous studies to characterise different types of foragers and terminology according to the modified scoutrecruit concept

\begin{tabular}{|c|c|c|}
\hline Source & Terminology used by authors & New terminology \\
\hline von Frisch $(1923,1967 / 1993)$ & $\begin{array}{l}\text { Primary searchers (Primären Sucher) } \\
\text { Secondary searchers (Sekundären Sucher) } \\
\text { Scouts (known source; Kundschafter) } \\
\text { Aroused experienced bees } \\
\text { Collectors (Sammlern) }\end{array}$ & $\begin{array}{l}\text { Scouts } \\
\text { Recruits } \\
\text { Inspectors } \\
\text { Reactivated foragers } \\
\text { Employed foragers }\end{array}$ \\
\hline zu Oettingen-Spielberg (1949) & $\begin{array}{l}\text { Inexperienced search bees } \\
\quad \text { (Suchbienen; first part of study: no external information) } \\
\text { Inexperienced search bees } \\
\quad \text { (Suchbienen; second part: activated by round dances) } \\
\text { Collectors scouting before food provisioning }\end{array}$ & $\begin{array}{l}\text { Scouts } \\
\text { Recruits } \\
\text { Scouts }\end{array}$ \\
\hline Lindauer $(1952,1953)$ & $\begin{array}{l}\text { Scouts } \\
\text { Young field bees following dances }\end{array}$ & $\begin{array}{l}\text { Scouts } \\
\text { Recruits }\end{array}$ \\
\hline Seeley (1983) & $\begin{array}{l}\text { Scouts } \\
\text { Recruits } \\
\text { Bees checking known source } \\
\text { Scouts, i.e. bees locating patches other than that indicated } \\
\quad \text { in dance they followed }\end{array}$ & $\begin{array}{l}\text { Scouts } \\
\text { Recruits } \\
\text { Inspectors } \\
\text { Recruits }\end{array}$ \\
\hline Crawford and Rissing (1983) & $\begin{array}{l}\text { Scout, i.e. ant captured randomly } \\
\text { Recruit, i.e. ant guided to food source }\end{array}$ & $\begin{array}{l}\text { Scout or inspector } \\
\text { Recruit or reactivated forager }\end{array}$ \\
\hline Pereboom and Sommeijer(1993) & $\begin{array}{l}\text { Recruits } \\
\text { Scouts, i.e. revisiting known source }\end{array}$ & $\begin{array}{l}\text { Reactivated foragers, } \\
\text { probably some recruits } \\
\text { Inspectors }\end{array}$ \\
\hline Fourcassié and Traniello (1994) & Naive foragers & Inspectors \\
\hline Howard et al. (1996) & $\begin{array}{l}\text { Scouts } \\
\text { Recruits }\end{array}$ & $\begin{array}{l}\text { Scouts } \\
\text { Recruits }\end{array}$ \\
\hline Dreller (1998) & $\begin{array}{l}\text { Scouts } \\
\text { Recruits }\end{array}$ & $\begin{array}{l}\text { Scouts } \\
\text { Recruits }\end{array}$ \\
\hline
\end{tabular}

known feeder by means of round dances ( $89 \%$ of bees returned to a known feeder within $10 \mathrm{~min}$ ) or through antennal contact alone (39\% efficiency). Unemployed experienced foragers were reactivated by any stimulation with a familiar odour. That is, these bees were reactivated through injection of scented sugar water into the hive, and also through dances for another similarly scented food source. They were not reactivated by round dances for differently scented food sources. von Frisch also studied recruitment of novice foragers ('sekundären Sucher': bees at least unfamiliar with the training feeder) by means of round dances performed by collectors ('Sammlern') or primary searchers ('primären Sucher'). In our terms, the collectors are called employed foragers, the primary searchers are scouts and the secondary searchers are recruits.

In the first part of the study of zu Oettingen-Spielberg (1949; Fig. 3b), searching behaviour of novice foragers was observed while any possible information exchange with experienced foragers was excluded (transition 1). She refers to these inexperienced, uninformed search bees as 'Suchbienen' which has been translated as scouts (von Frisch 1950; Ribbands 1953), and which is the same term we propose. In the second part of her study, a food source (scented pollen and nectar) was provided to the colonies and the approaches to this food source and to differently scented flowers were observed (transition 2). She found that $95 \%$ of the individually marked novice foragers found the feeder advertised by the employed foragers visiting it, whereas $5 \%$ of them found the flowers (both called 'Suchbienen' in her terminology). We refer to the first group as recruits since they probably followed dances performed by the employed foragers. The latter group should be referred to as recruits, if they were guided by dances (or more specifically, 'lost recruits', since they located a different food source than indicated), but are scouts if they started searching spontaneously. In addition, some of the employed foragers located the flowers, but almost exclusively before food was provided at the feeder. zu Oettingen-Spielberg (1949) refers to these bees also as scouts. According to our concept, they follow the trajectory from employed bee via inspector to unemployed bee (end of previous food provisioning; Fig. 3b, trajectory $3-4)$, then they (probably) inspect the feeder in vain (transition 5), become unemployed and finally scout for 
something new and locate the flowers (transition 6). The information on the few bees that located the flowers while food was provided is too fragmentary (not individually marked) to draw any conclusions on their trajectory. It would be highly surprising (and problematic for our concept) if they had changed to searching while their food source still provided food. This would be behaviour typical for solitarily foraging individuals.

The terminology that Lindauer (1952, 1953; Fig. 3c) uses largely agrees with ours, with the only difference that he distinguishes honey-bees based upon their finds. His scouts are true scouts and the remaining 'young field bees' followed dances and are recruits according to our terminology. Interestingly, he distinguishes between recruits that find the indicated source and those that find another source (which could be referred to as 'lost recruits'; see below).

Seeley (1983; Fig. 3d; see also Seeley and Visscher 1988 ) repeated the study of Lindauer (1952) with experienced bees, i.e. previously employed but now unemployed bees. He studied individual behaviour after he shut down the sugar water feeder they were accustomed to feed on. Then he called the bees going out without following dances, scouts (similar to our terminology), and the bees following dances before searching for food, recruits (similar to our terminology). Moreover, he noted that all bees performed a few trips to check the old feeder (inspectors in our terminology). The trajectory of these bees is thus (see Fig. 3d): (1) being recruited [in fact trained to the feeder; some individuals (scouts) may have discovered it independently]; (2) becoming an employed forager; (3) repeatedly visiting the feeder (still employed forager); (4) becoming unemployed after feeder was shut down; (5-6) inspector of old feeder (repeatedly but in vain); (7) either follow dances to become a recruit or start searching independently to become a scout. As mentioned before, some recruits found patches other than those indicated by the dances they followed. These bees would be recruits in our concept (more specifically, 'lost recruits'), but are transferred to the ranks of the scouts by Seeley (1983).

Crawford and Rissing (1983) captured a random ant (they called the scout), transferred it to a feeder, after which it fed and returned to its colony. They then observed the number of ants it brought to the feeder. All ants were placed back into the colony after the experiment. The experiment was repeated every 2 days. In this study it is not clear (1) what was the status of the captured ant (scout or inspector) and (2) whether the recruits were inexperienced or temporarily unemployed (since the previous experiment).

Pereboom and Sommeijer (1993) followed previous authors (e.g. von Frisch 1967/1993) when they called the reactivation of experienced stingless bee foragers recruitment. Individual bees figured in more than one experiment and experience probably facilitated their reactivation (see von Frisch 1923; Biesmeijer and Ermers 1999). The bees that turned up at the source in the experimental series (all arriving bees were captured) would in our concept be referred to as inspectors, and not as scouts, the term used by the authors. On the other hand, at least some of the bees arriving in the control series (free flight between feeder and hive) would be called reactivated foragers in our concept instead of recruits as was done by Pereboom and Sommeijer (1993).

Fourcassié and Traniello (1994; Fig. 3e) studied foodsearching behaviour of 'naive ant foragers'. According to our concept, they studied the inspection behaviour of experienced foragers. They captured an outgoing ant, fed it carbohydrate or protein ad libitum, then placed it in the test runway. When it entered a specified arena it was given food (either protein or carbohydrate). It then returned to the hive and was observed to analyse its searching behaviour. The trajectory of these foragers was thus (Fig. 3e): (1) status unknown, either scout, recruit or inspector (go out of nest), (2) employed forager (being fed in the capture box is similar to the experience of an employed forager), searching/walking in runway (status not present in concept, but artificial), employed forager again (given food once upon entering arena), and (3) inspector (searching behaviour in previously rewarding arena). Therefore, according to our terminology, the tested ants were not at all naive: although they did not have extensive experience, it was clearly enough to perform memory-guided inspection behaviour.

Howard et al. (1996) categorise scouts and recruits in leaf-cutting ants using terminology similar to ours, based upon spontaneous or guided (pheromone trail following) search behaviour.

Dreller (1998; Fig. 3f) shows that there is genetic determination of scouts and recruits in honey-bees. Therefore, it is of particular importance to review in detail which bees she called scouts and which recruits. Scouts in her study are all returning foragers carrying either pollen or nectar after the colony had been moved $5 \mathrm{~km}$ away overnight. She states that the bees perceived the new site indeed as new, because all bees oriented towards the hive entrance the first time they went out foraging after the overnight displacement. It is well known that even after moving a colony, (some of) the experienced bees go out first. von Frisch (1923, p. 45) describes how the morning after moving a small observation hive to an enclosed greenhouse, one-third of all bees, the experienced foragers, flew to the glass roof of the greenhouse and died. Only in the afternoon did young bees start their orientation flights and found the food he had put out. Moreover, Melipona stingless bees oriented again before resuming foraging after their colony had been taken on a short bumpy car ride, although they were replaced at their previous location (S. Lukács, personal communication). It seems very plausible, therefore, that the bees that in Dreller's set-up collected pollen or nectar after the displacement were experienced bees inspecting the area for known food sources. They had probably previously followed the trajectory: (1) scout/recruit; (2) employed forager; (3) inspector, and (4) unemployed forager. Obviously, the area after displacement was unknown to them and they could not re- 
turn to their previous food source. On the other hand, it seems highly unlikely that over a distance of $5 \mathrm{~km}$, the available food plants are different, making it plausible that the bees located a new patch of the food type familiar to them. Unfortunately, Dreller did not analyse the loads to reveal whether the inspectors had merely collected the same food type from another patch or something completely different. In a later experiment, using two identifiable genetic strains that show high and low pollen hoarding, again the previous experience of the socalled scout bees is not taken into account in the analysis. She argues that scouts of the high-pollen-hoarding strain preferentially search for pollen sources. However, this preference could merely reflect the genetically based preference they showed in previous foraging (see also Page and Fondrk 1995) and not a genetically based scouting preference. We presume that the bees performed inspection behaviour and, after not locating the known source, located new patches of the known food plant. This is certainly some type of scouting behaviour, and the bees would go through the trajectory (Fig. 3f): (5) inspector to (6) unemployed forager to (7) scout, but it might be different from the scouting behaviour of novice foragers.

In a previous study (Biesmeijer et al. 1998), we use the terms employed, unemployed and novice forager in the same sense as in the concept presented here. However, the experienced foragers that restart foraging after having received information (p. 114) should be referred to as reactivated foragers and the bees checking a known food source (p. 113) we now call inspectors.

\section{Necessity and sufficiency of forager categories and transitions}

von Frisch (1923, 1967) already distinguished five behavioural types of foragers (Table 3). Moreover, the two remaining types were implicitly recognized in the early literature (novice foragers: von Frisch 1923; Lindauer 1952; zu Oettingen-Spielberg 1949; unemployed foragers: von Frisch 1923). The importance of distinguishing the seven forager states we propose here became obvious while modelling honey-bee nectar-foraging behaviour (de Vries and Biesmeijer 1998). In particular, the separation of experienced foragers (inspectors, reactivated bees) from inexperienced search bees (scout, recruit) made the collective foraging behaviour more intelligible. The seven categories appear to be necessary and sufficient to describe all the foraging behaviours from previous studies (Table 3, Fig. 3).

The other essential aspect of the modified concept concerns the transitions between the different states. Figure 3 shows that most of the transitions proposed are supported by empirical data. In addition, the studies we evaluated did not show transitions not present in the concept. There is only one exception. Data of zu OettingenSpielberg (1949) suggest that a transition from collecting food (being employed) to searching for new food sources (being an experienced scout) is also possible. Such behaviour is well known from the individually foraging bumble-bees that tend to collect most food from one plant species (their major source) while occasionally using other foods (their minor sources) (Heinrich 1976, 1979). More information on social foraging insects is needed to determine whether this behaviour represents a new transition between states (employed forager to scout). The transition from employed forager directly to unemployed forager can occur in honey-bees (Seeley 1995, p. 143). Foragers tend to abandon a food source after experiencing poor foraging there or when finding a receiver bee to transfer her nectar takes too long. The time it takes to find a receiver bee is influenced by the colony's total rate of nectar intake. This means that the forager may abandon her nectar source, even if its profitability has not changed, if nest mates discover additional nectar sources. As a result, employed foragers become unemployed when they abandon the constant source solely on the basis of information obtained in the nest.

One of the advantages of the concept is that different studies and species can be compared more explicitly by analysing forager categories and transition probabilities (Fig. 3). The experimental protocols can be depicted using the scheme of Fig. 2 (as has been done in Fig. 3a-f), and the trajectories followed by the foragers and the choices they have made become immediately apparent.

For example, in Seeley's (1983) study, the honey-bees were initially trained to a sugar water feeder [Fig. 3d, trajectory 1-2-3: novice foragers become recruits (or scouts) and then employed foragers]. Then the feeder was removed, converting employed foragers into unemployed foragers (transition 4). The options available to these experienced bees the next morning during the actual test were: (1) inspect the old source; (2) scout for new food, or (3) follow recruitment dances. All bees chose option 1 first (transition 5), without success since the feeder was empty (transition 6). This behaviour repeated itself several times before the actual decision was made whether to scout or follow dances (transition 7). Detailed analysis of the subsequent behaviour of scouts (23\% of the bees) and recruits (77\%) provides us with probabilities for several transitions (see Fig. 3d, transition 8-9). Figure 3 also reveals that the four major studies investigating division of labour between scouts and recruits (zu Oettingen-Spielberg 1949; Lindauer 1952; Seeley 1983; Dreller 1998) each used a different experimental design. Seeley (1983) used bees trained to a feeder, thus largely recruits, whereas zu Oettingen-Spielberg (1949) either prevented recruitment (by capturing all bees arriving at the source) or provided a feeder, but then studied the 'lost recruits'. The other two studies used undisturbed naturally foraging colonies, but Lindauer's (1952) analysis focussed on the beginning of the foraging history, whereas Dreller (1998) mainly observed experienced foragers that had already finished the first part of the trajectory studied by Lindauer. Consequently, comparing these studies is difficult, because the bees investigated had different trajectories, were in different states and thus chose from different behavioural options. 


\section{The exploration process: who discovers new food sources?}

According to the new concept, three types of foragers can discover new food sources: (1) novice bees that become scouts; (2) experienced, unemployed foragers that become scouts, and (3) recruits that find something other than indicated by the external information they used to start searching ('lost recruits'). All three types appear to exist in ants and bees. We consider any addition to the colony's food source repertoire as part of the exploration process. This includes finding a new type of food at a previously visited site as well as the same type of food at a new site.

\section{Specialised scouts}

The two ways in which the foraging tasks can be partitioned are: (1) all bees have a disposition for scouting, or (2) only some individuals have a scouting disposition (Seeley 1983; Dreller 1998). There seems to be evidence supporting both hypotheses. zu Oettingen-Spielberg (1949) concludes that scouts can be experienced or inexperienced and of any age. Lindauer (1952) clearly shows that scouting is a temporary role of foragers. None of the 23 bees that switched food sources during his observations behaved exclusively as a scout: 1 bee scouted her first food source, but was recruited to the next source; 10 other bees were recruited to their first food source, but apparently scouted their second ( 9 bees) or third ( 1 bee, plus 1 of the former group) food source, and 12 bees were recruited to all of their food sources (two sources: 9 bees; three sources: 2 bees; four sources: 1 bee). Additional support is provided by the studies of Seeley (1983) and Seeley and Visscher (1988), because they observed that recruits (bees first trained to a feeder) can become both scouts and recruits. Dreller (1998) determined, using destructive sampling, that there is a genetic basis to being a scout or recruit. This seems to suggest that scouts are (genetically determined) specialist explorers. She argues that (p. 195) "the finding that specialisation takes place basically by genetic differences together with Lindauer's observation that some bees never follow dances makes it very likely that scouts always search independently for food." However, in Lindauer's study, none of the bees that collected from more than one food source always scouted, but 11 bees both scouted and were recruited during their career. Seeley (1983, p. 257) also suggests that some bees might first scout independently, and then follow dances. Although it would be logical to expect that genetically based differences in individual scouting tendency play their role in naturally foraging colonies (Seeley 1985, p.85), the evidence cited above suggests that other factors are at least as important. This idea is supported by the results of Pasteels et al. (1987) that show that through simple learning rules (feedback loops using previous experience), a group of initially identical foragers spontaneously divides into highly active and less active individuals. Moreover, it seems much more adaptive for a colony to use a flexible allocation of novice bees among scouting and being recruited, because food availability changes rapidly and unpredictably (Visscher and Seeley 1982; Traniello 1987; Sundström 1993). Further studies are needed to reveal the presence and relative importance of genetic disposition for scouting behaviour in social insects.

The proportion of novice bees in a colony's forager force that become scouts is apparently very low. Lindauer (1952) observed that only 9 of 159 novice honey-bee foragers $(5.7 \%)$ scouted for food. zu OettingenSpielberg (1949) states that although 600-700 honeybees were flying around in her flight cage, only about 1 bee discovered the flowers she put out for $1 \mathrm{~h}$, and that was the only food source available to the bees. From a larger colony, ten bees arrived independently at the flowers each hour.

\section{Unemployed experienced foragers}

The importance of these explorers, i.e. bees that have previously visited food sources and are temporarily unemployed, is confirmed by Seeley (1983), Seeley and Visscher (1988), zu Oettingen-Spielberg (1949), Dreller (1998) and Lindauer (1952). Seeley showed that 23\% of experienced unemployed foragers whose source has terminated scout independently for food. Lindauer observed that 10 of 23 experienced honey-bee foragers locate a food source independently. zu Oettingen-Spielberg (1949) observed that only 2 of 280 foragers with 4 days experience on a feeder scouted the alternative, differently scented feeder placed $26 \mathrm{~cm}$ from the previous feeder location, when their usual feeder did not contain food (the remaining bees only inspected the previous feeder). In Seeley's (1983) set-up, experienced bees could only locate a completely new food source, because no food was available at the same location or of the same odour. In Dreller's (1998) study, experienced bees could scout food of the same odour but only at new locations.

Solitarily foraging desert ants maintain constant bearings throughout their foraging life (Wehner et al. 1983), this tendency becoming stronger with an increase in previous success (Wehner 1987). Honey-bee and bumble-bee foragers restrict their foraging to a small area even in extensive fields (Singh 1950; Heinrich 1976). This suggests that an individual's internal information biases its scouting behaviour and the acceptance of different food sources.

\section{'Lost' recruits}

Pasteels et al. (1987) observed that in the ant Tetramorium caespitum, one-third of the recruits that started following a pheromone trail lost it before locating the food source to which it led. They called these ants 'lost recruits' and suggested that these individuals might accidentally discover new food sources. 
The proportion of lost recruits differs strongly among ant species. Deneubourg et al. (1983) found that $81.8 \%$ of the recruits lost the scent trail in T. impurum, whereas only $26.4 \%$ of Tapinoma erraticum recruits lost their trail. Seeley (1983) showed that experienced honey-bee foragers that followed dances for a new food source needed 4.8 \pm 3.2 dance-guided flights to find the indicated food source (21\% recruitment success rate). One of 31 dance followers found a patch other than indicated by the dances. Lindauer (1952) found that 14 of 52 novice recruits $(27 \%)$ discovered a new source (1 bee found other material at same site, 5 bees found other material at another site, 4 bees found the same material at another site, 4 bees found other material at an unknown site). Moreover, 2 bees collected nectar instead of pollen from the same plant species in the same area indicated by the round dances they followed.

Most communication systems used by social insects are not very accurate, one of the more precise mechanisms probably being odour trail laying as performed by many ants (Hölldobler and Wilson 1990) and several stingless bees (Lindauer and Kerr 1958). This led Deneubourg et al. (1983) to propose that the 'errors' in recruitment communication might be adaptive and tuned to particular ecological conditions. Towne and Gould (1988) provided evidence for that hypothesis in honeybees and it is now generally referred to as the tuned-error hypothesis. A recent study by Weidenmüller and Seeley (1999) shows that recruitment dances of honey-bee scouts advertising nest sites are much more accurate (narrow divergence angle in waggle runs) than the recruitment dances for an equidistant food source (wide divergence angle in waggle runs). This strongly suggests that recruits are sent out to find a certain type of food in a relatively large area around the previously discovered food plants.

Lost recruits might form a very important group in the exploration strategy of most social insect colonies and, like the group of experienced scouts, decrease the need for specialised scouts.

Few studies provide data for all three groups of explorers. Lindauer (1952) observed that 6\% of novice honey-bees scouted, and $43.5 \%$ of the experienced foragers. Moreover, $27 \%$ of the recruits were successful 'lost recruits'. It would be of great interest to examine more extensively the exploration side of a bee, ant or wasp colony's foraging strategy. In particular because theoretical studies indicate that the optimal investment in exploration changes with colony size, recruitment mechanism, resource density and resource size (Jaffe and Deneubourg 1992).

Acknowledgements We would like to express our gratitude to Judith Slaa, Arco de Groot, Marinus Sommeijer, Thomas Seeley, Robin Moritz and an anonymous referee for commenting on the conceptual ideas and manuscript. This study was supported by the Netherlands Foundation for the Advancement of Tropical Research (WOTRO) grant W84-471 to M.J. Sommeijer.

\section{References}

Biesmeijer JC, Ermers MCW (1999) Social foraging in stingless bees: how colonies of Melipona fasciata choose among nectar sources Behav Ecol Sociobiol 46:129-140

Biesmeijer JC, Nieuwstadt MGL van, Lukács S, Sommeijer MJ (1998) The role of internal and external information in foraging decisions of Melipona workers (Hymenoptera: Meliponinae). Behav Ecol Sociobiol 42:107-116

Bonnier G (1906) Sur la division du travail chez les abeilles. Acad Sci Paris 143:941-946

Concise Oxford Dictionary (1991). Oxford University Press, Oxford

Crawford DL, Rissing SW (1983) Regulation of recruitment by individual scouts in Formica oreas Wheeler (Hymenoptera, Formicidae), Insectes Soc 30 177-183

Deneubourg JL, Pasteels JM, Verhaeghe JC (1983) Probabilistic behavior in ants: a strategy of errors? J Theor Biol 105 259-271

Deneubourg JL, Goss S, Pasteels JM, Fresneau D, Lachaud JP (1987) Self-organisation mechanisms in ant societies. (II). Learning in foraging and division of labour. Experientia (suppl) 54:177-196

Dreller C (1998) Division of labor between scouts and recruits: genetic influence and mechanisms. Behav Ecol Sociobiol 43:191-196

Fourcassié V, Traniello JFA (1994) Food searching behaviour in the ant, Formica schaufussi (Hymenoptera, Formicidae): response of naive foragers to protein and carbohydrate food. Anim Behav 48:69-79

Frisch K von (1918) Über den Geruchsinn der Biene und seine Bedeutung für den Blumenbesuch. II. Mitteilung. Verh ZoolBot Ges Wien 65:129-144

Frisch K von (1919) Über den Geruchsinn der Biene und seine blütenbiologische Bedeutung. Zool Jahrb 37:1-238

Frisch K von (1923) Über die "Sprache" der Bienen, eine tierpsychologische Untersuchung. Zool Jahrb 40:1-186

Frisch K von (1950) Bees: their vision, chemical senses, and language. Cornell University Press, Ithaca, NY

Frisch K von (1967/1993) The dance language and orientation of bees. Harvard University Press. Cambridge, Mass

Goodwin B, Dawkins R (1995) What is an organism? A discussion. In: Thompson NS (ed) Perspectives in ethology, vol 11. Behavioural design. Plenum, New York, p47-60

Heinrich B (1976) The foraging specializations of individual bumblebees. Ecol Monogr 46:105-128

Heinrich B (1979) Bumblebee economics. Harvard University Press, Cambridge, Mass

Hölldobler B, Wilson EO (1990) The ants. Harvard University Press, Cambridge, Mass

Howard JJ, Henneman ML, Cronin G, Fox JA, Hormiga G (1996) Conditioning of scouts and recruits during foraging by a leafcutting ant, Atta colombica. Anim Behav 52:299-306

Jaffe K, Deneubourg JL (1992) On foraging, recruitment systems and optimum number of scouts in eusocial colonies. Insectes Soc 39:201-213

Johnson LK (1983) Foraging strategies and the structure of stingless bee communities in Costa Rica. In: Jaisson P (ed) Social insects in the tropics, vol 2. Université de Paris-Nord, Paris

Lindauer M (1952) Ein Beitrag zur Frage der Arbeitsteilung im Bienenstaat. Z Vergl Physiol 34:299-345

Lindauer M (1953) Division of labour in the honeybee colony. Bee World 34: 63-73, 85-90

Lindauer M (1955) Schwarmbienen auf Wohnungssuche. Z Vergl Physiol 37:263-324

Lindauer M (1957) Communication in swarm-bees searching for a new home. Nature 179:63-66

Lindauer M, Kerr WE (1958) Die Gegenseitige Verständigung bei den stachellosen Bienen. Z Vergl Physiol 41:405-434

Maeterlinck M. (1901/1946) The life of the bee. Allen \& Unwin, London 
Oettingen-Spielberg T zu (1949) Über das Wesen der Suchbiene. Z Vergl Physiol 31:454-489

Opfinger E (1949) Zur Psychologie der Duftdressuren bei Bienen. Z Vergl Physiol 31:441-453

Page RE, Fondrk MK (1995) The effects of colony-level selection on the social organization of honey bee (Apis mellifera L.) colonies: colony-level components of pollen-hoarding. Behav Ecol Sociobiol 36:135-144

Pasteels JM, Deneubourg JL, Goss S (1987) Self-organization mechanisms in ant societies. I. Trail recruitment to newly discovered food resources Experientia (suppl) 54:155-177

Pereboom JJM, Sommeijer MJ (1993) Recruitment and flight activity of Melipona favosa, foraging on an artificial food source. Proc Exp Appl Entomol 4:73-78

Ribbands CR (1953) The behaviour and social life of honeybees. Bee Research Association, London

Seeley TD (1983) Division of labor between scouts and recruits in honeybee foraging. Behav Ecol Sociobiol 12:253-259

Seeley TD (1985) The information-center strategy of honeybee foraging. In: Hölldobler B, Lindauer M (eds) Experimental behavioural ecology. Fischer, Munich, p75-90

Seeley TD (1995) The wisdom of the hive. Harvard University Press, Cambridge, Mass

Seeley TD, Visscher PK (1988) Assessing the benefits of cooperation in honeybee foraging: search costs, forage quality, and competitive ability. Behav Ecol Sociobiol 22:229-237
Singh S (1950) Behaviour studies of honeybees in gathering nectar and pollen. Mem Cornell Univ Agric Exp Station 288:1-57

Sundström L (1993) Foraging responses of Formica truncorum (Hymenoptera; Formicidae): exploiting stable vs spatially and temporally variable resources. Insectes Soc 40:147-161

Towne WF, Gould JL (1988) The spatial distribution of the honey bees' dance communication. J Insect Behav 1:129-155

Traniello JFA (1987) Social and individual responses to environmental factors in ants. Experientia (suppl) 54:63-81

Visscher PK, Seeley TD (1982) Foraging strategy of honeybee colonies in a temperate deciduous forest. Ecology 63:1790 1801

Vries H de, Biesmeijer JC (1998) Modelling collective foraging by means of individual behaviour rules in honey-bees. Behav Ecol Sociobiol 44:109-124

Wehner R (1987) Spatial organization of foraging behaviour in individually searching desert ants, Cataglyphis (Sahara desert) and Ocymyrmex (Namib desert). Experientia (suppl) 54:15-42

Wehner R, Harkness RD, Schmid-Hempel P (1983) Foraging strategies in individually searching ants Cataglyphis bicolor (Hymenoptera: Formicidae). Fischer, Stuttgart

Weidenmüller A, Seeley TD (1999) Imprecision in waggle dances of the honey bee (Apis mellifera) for nearby food sources: error or adaptation? Behav Ecol Sociobiol 46:190-199

Winston M (1987) The biology of the honey bee. Harvard University Press, Cambridge, Mass 